American Journal of Biochemistry and Biotechnology 3 (3): 171-179, 2007

ISSN 1553-3468

(C) 2007 Science Publications

\title{
Colourimetric Determination of Phospholipase Activities in Balamuthia mandrillaris
}

\author{
Syed Razi Haider \\ School of Biological and Chemical Sciences Birkbeck College \\ University of London, WCIE 7HX London England UK
}

\begin{abstract}
Balamuthia mandrillaris is a recently identified protozoan pathogen that can cause fatal granulomatous encephalitis however the pathogenesis and pathophysiology associated with Balamuthia encephalitis remain unclear. We have recently isolated B. mandrillaris from a 33-years old male who died of encephalitis. Using this isolate, we demonstrated for the first time that $B$. mandrillaris exhibited phospholipase activities. More specifically, B. mandrillaris exhibited phospholipase $\mathrm{A}_{2}$ and phospholipase $\mathrm{D}$ activities. For the first time we used colourimetric technique based on spectrophotometer and designed phospholipases assays to determine these phospholipase activities. The functional role of phospholipases was determined in in vitro assays using human brain microvascular endothelial cells (HBMEC). We observed that $\mathrm{PLA}_{2}$-specific inhibitor i.e., cytidine 5'diphosphocholine significantly inhibited $B$. mandrillaris binding to HBMEC. Similarly PLD inhibitor i.e., compound 48/80 inhibited B. mandrillaris binding to HBMEC. Moreover, both inhibitors inhibited $B$. mandrillaris-mediated HBMEC cytotoxicity. Overall these results clearly demonstrate that phospholipases are important virulence determinants in B. mandrillaris. Further studies will identify the precise role of phospholipases in the pathogenesis of $B$. mandrillaris, which may help develop therapeutic interventions. Using a novel spectrophotometric-based assay we demonstrated for the first time that $B$. mandrillaris exhibit phospholipase activities.
\end{abstract}

Key words: Balamuthia mandrillaris, Phospholipase $\mathrm{A}_{2}$, Phospholipase D, Adhesion, Cytotoxicity

\section{INTRODUCTION}

Balamuthia mandrillaris is a recently discovered protozoan pathogen that can cause fatal granulomatous encephalitis. It is believed that this organism is widely distributed in fresh water, soil and dust throughout the world. The first known isolate of this amoeba was from a mandrill Baboon who died of $B$. mandrillaris granulomatous encephalitis (BGE) [1]. The first time $B$. mandrillaris was recognised as causing encephalitis in humans in 1990 when first case was reported at Santa Cruz hospital California U.S.A [2]. Since then more than 105 fatalities attributed to B. mandrillaris [3] [4]. There have been only two survivors of BGE [5]. Thus the mortality is more than $98 \%$.

Phospholipases are the enzymes, which catalyse the hydrolysis of specific ester bonds in phospholipids. Individuals enzymes are grouped on the basis of the bond they hydrolyse and are further categorized. The phospholipases are thus called phospholipase A, B, C and D. For the phospholipase A, a subscript 1 or 2 is added depending on whether the cleaved bond involved is at the sn-1 or sn-2, position of the phospholipid substrate.

The term phospholipase A is used for those enzymes, which catalyse the hydrolysis of the terminal or central acyl group from a membrane phospholipid.

Phospholipase $\mathrm{A}$ is further classified into phospholipase $\mathrm{A}_{1}\left(\mathrm{PLA}_{1}\right)$ and phospholipase $\mathrm{A}_{2}\left(\mathrm{PL} \mathrm{A}_{2}\right)$.

Phospholipase $\mathrm{A}_{1}$ catalyzes the hydrolysis of the terminal acyl group from a phospholipid, generating a free fatty acid and a lysophospholipid and referred to as PLA $_{1}$ because of its 1-acyl specificity. Phospholipase $\mathrm{A}_{2}$ represents a class of heat-stable calcium-dependent enzymes catalyzing the hydrolysis of the 2-acyl bond of 3-n-phosphoglycerides, generating a free fatty acid and a lysophospholipid. This enzyme is named phospholipase $\mathrm{A}_{2}$ to denote its 2-acyl specificity. Phospholipase $\mathrm{A}_{2}$ enzyme plays a significant role in the liberation of arachidonic acid from the $s n-2$ position of cellular phospholipids in most mammalian cells. The released arachidonic acid is used in many cases of the biosynthesis.

Phospholipase B (PLB) (synonyms: lysophospholipase, lysophospholipase-transacylase) refers to an enzyme that can remove both $s n-1$ and $s n-2$ fatty acids, its

Corresponding Author: Dr. Salman Al Rokayan, Department of Biochemistry, College of Science, King Saud University, P.O. Box 2455, Riyadh 11451, Kingdom of Saudi Arabia 
nomenclature is confusing. This confusion arises because PLB has both hydrolase (fatty acid release) and lysophospholipase-transacylase (LPTA) activities. The hydrolase activity allows the enzyme to cleave fatty acids from both phospholipids (PLB activity) and lysophospholipids [lysophospholipase (Lyso-PL] activity)], while the transacylase activity allows enzyme to produce phospholipid by transferring a free fatty acid to lysophospholipid.

Phospholipase $\mathrm{C}$ enzymes catalyze the hydrolysis of the phosphoric ester bond of a membrane phospholipid and generate a phosphorylated alcohol and diacylglycerol. They are important in the digestion of dietary phospholipids and in various processes dependent on hormonally induced calcium mobilization or arachidonic acid production, they occur in all mammalian tissues and as toxic secretion products of pathogens.

Phospholipase D enzymes catalyze the hydrolysis of the alcohol group from a phospholipid, and generate the corresponding phosphatidate. They occur in various forms, predominantly in plants (e.g. cabbage), but in humans they may be a part of a mechanism to generate diacylglycerol for the mobilization of calcium in response to hormones. These enzymes are nonhaemolytic but only in the presence of the cholesterol oxidase these PLDs show haemolytic activity. These enzymes have generally not been well studied but some of them are haemolysin, which are active preferentially towards sphingomyelin and degrades phospholipids [6]. The aim of this study was to determine Balamuthia mandrillaris special emphasis on their possible role in the virulence of this pathogen.

\section{MATERIALS AND METHODS}

Human brain microvascular endothelial cells (HBMEC): Primary brain microvascular endothelial cells from human origin were obtained from our collaborator (Prof. K. S. Kim, John Hopkins University Baltimore, MA, USA). HBMEC were routinely grown in tissue culture flasks in RPMI containing $10 \%$ heat inactivated fetal bovine serum, 10\% Nu-Serum, $2 \mathrm{mM}$ glutamine, $1 \mathrm{mM}$ pyruvate, penicillin $(100 \mathrm{U} / \mathrm{ml})$, streptomycin $(100 \mu \mathrm{g} / \mathrm{ml}), 1 \%$ non-essential amino acids and $1 \%$ vitamins as previously described [7]. Media reagents were filtered using $0.2 \mu \mathrm{M}$ pore size filter and stored at $4^{\circ} \mathrm{C}$ and used within two weeks. Briefly, HBMEC were collected using trypsin and transferred into a $50 \mathrm{ml}$ centrifuge tube. The cells were centrifuged at $750 \mathrm{xg}$ for $5 \mathrm{~min}$. The supernatants were aspirated and the pellet resuspended into fresh HBMEC media and inoculated into flasks. Flasks were incubated at $37^{\circ} \mathrm{C}$ in $5 \% \mathrm{CO}_{2}$ incubator. For cytotoxicity and adhesion assays, HBMEC were grown into 24-well plates by inoculating $5 \times 10^{5} \quad$ cells $/$ well $/ \mathrm{ml}$. At this cell density, HBMEC formed confluent monolayers within $24 \mathrm{~h}$ and used for assays.

Balamuthia mandrillaris cultures: Two isolates of $B$. mandrillaris were used. First isolate was from the brain of a mandrill baboon (ATCC VO39) and the second isolate from the brain of a 33-year old patient who died of encephalitis [8]. Both isolates were cultured using HBMEC monolayers as food source. Briefly, $5 \times 10^{5} \mathrm{~B}$. mandrillaris were incubated with HBMEC in serum free media (RPMI containing $2 \mathrm{mM}$ glutamine, $1 \mathrm{mM}$ pyruvate and $1 \%$ non-essential amino acids). Flasks were incubated at $37^{\circ} \mathrm{C}$ in a $5 \% \mathrm{CO} 2$ incubator and observed daily. HBMEC monolayer degradation was observed within 3-4 days and resulted in approximately $5 \times 10^{6}$ amoebae (more than 95\% amoebae in trophozoite forms).

Balamuthia mandrillariswere subsequently used in phospholipases, adhesion and cytotoxicity assays.

Phospholipase assays: Phospholipase D and Phospholipase $\mathrm{A}_{2}$ activities were determined by using a spectrophotometric-based assay.

Phospholipase D assays: Briefly, the trophozoite forms of B. mandrillaris were collected. Various cell numbers were pelleted by centrifugation at $750 \mathrm{x} g$ and resuspended in $0.1 \mathrm{ml}$ of phosphate buffered saline (PBS). The parasite cultures were frozen at $-80^{\circ} \mathrm{C}$ (approx. $20 \mathrm{~min}$ ). Following this, cultures were thawed at room temperature and vortexed. This process was repeated $4 \mathrm{X}$ and resulted in complete cell lysis, (confirmed by observing under the microscope). The lysates were incubated with $0.9 \mathrm{ml}$ of cold substrate solution [0.14 M choline chloride (stock solution was prepared by dissolving in $0.1 \mathrm{M}$ Tris- $\mathrm{HCl}$ buffer, $\mathrm{pH}$ 8.0), $0.48 \mathrm{mM}$ 4-aminoantipyrine (stock solution was prepared in $\mathrm{H}_{2} \mathrm{O}$ ), $2.1 \mathrm{mM}$ phenol (stock solution was prepared in $\left.\mathrm{H}_{2} \mathrm{O}\right), 4.92 \mathrm{U} / \mathrm{ml}$ peroxidase from horseradish (110 purpurogallin units/mg, Toyobo Grade III)]. The mixtures were incubated at various temperatures. The substrate solutions without $B$. mandrillaris lysates were used as blanks. In addition, $B$. mandrillaris lysates, incubated with PBS alone, were used as negative controls. Following this incubation, mixtures were transferred into cuvettes and determined 
their absorbance values at $500 \mathrm{~nm}$. The absorbance values were converted into Units per $\mathrm{ml}$ activity as follows:

OD (sample) - OD (blank) $\quad \mathrm{Vt} / 12 \times 0.5 \times 1$ $\mathrm{x} \quad \mathrm{Vs}=$ Units per $\mathrm{ml}$ activity. OD is optical density, $\mathrm{Vt}$ is total volume of the cuvette, $\mathrm{Vs}$ is sample volume. 12 is millimolar extinction coefficient of quinoneimine dye under the assay conditions $\left(\mathrm{cm}^{2} /\right.$ micromole $), 0.5$ is a factor based on the fact that one mole of $\mathrm{H}_{2} \mathrm{O}_{2}$ produces half a mole of quinoneimine dye, 1 is light path length $(\mathrm{cm})$.

Phospholipase $\mathbf{A}_{\mathbf{2}}$ assay: The trophozoite forms of Balamuthia mandrillaris were collected. Various cell numbers were pelleted by centrifugation at $750 \mathrm{x}$ g and resuspended in $0.1 \mathrm{ml}$ of phosphate buffered saline (PBS). The parasite cultures were frozen at $-80^{\circ} \mathrm{C}$ (approx. $20 \mathrm{~min}$ ). Following this, cultures were thawed at room temperature and vortexed. This process was repeated $4 \mathrm{X}$ and resulted in complete cell lysis, (confirmed by observing under the microscope). The lysates were incubated with $0.9 \mathrm{ml}$ of cold substrate solution $[98 \mathrm{mM}$ D-L- $\alpha-$ glycerophosphate (stock solution was prepared by dissolving in $50 \mathrm{mM}$ Tris- $\mathrm{HCl}$ buffer, $\mathrm{pH}$ 8.0, contg. $0.049 \%$ triton- $\mathrm{x}-100), \quad 0.48 \quad \mathrm{mM} \quad 4-$ aminoantipyrine (stock solution was prepared in $\mathrm{H}_{2} \mathrm{O}$ ), $2.1 \mathrm{mM}$ phenol (stock solution was prepared in $\mathrm{H}_{2} \mathrm{O}$ ), $5.4 \mathrm{U} / \mathrm{ml}$ peroxidase from horseradish (110 purpurogallin units/mg, Toyobo Grade III)]. The mixtures were incubated at various temperatures. The substrate solutions without $B$. mandrillaris lysates were used as blanks. In addition, B. mandrillaris lysates incubated with PBS alone were used as negative controls. Following this incubation, mixtures were transferred into cuvettes and determined their absorbance values at $500 \mathrm{~nm}$. The absorbance values were converted into Units per $\mathrm{ml}$ activity as follows: OD (sample) - OD (blank) x Vt/ $13.3 \times 0.5 \times$ $1 \mathrm{x}$ Vs $=$ Units per ml activity. OD is optical density, Vt is total volume of the cuvette, Vs is sample volume 13.3 is millimolar extinction coefficient of quinoneimine dye under the assay conditions $\left(\mathrm{cm}^{2} /\right.$ micromole), 0.5 is a factor based on the fact that one mole of $\mathrm{H}_{2} \mathrm{O}_{2}$ produces half a mole of quinoneimine dye, 1 is light path length $(\mathrm{cm})$.

Adhesion assays: The purpose of the experiment was to determine if $B$. mandrillaris bind to in vitro to HBMEC. A $75 \mathrm{~cm}^{2}$ tissue culture flask containing the amoebae were examined under a light microscope. The amoebae could be assumed to be healthy if present in the trophozoite stage and appeared to be actively attached feeding trophozoites on the flask base. The amoebae cultures were collected by flask agitation. The flask was then examined under the microscope to check that amoebae were free in the RPMI 1640 medium and collected by centrifugation as described above. Next, amoebae were counted (amoebae $/ \mathrm{ml}$ ) using a haemocytometer. Balamuthia mandrillaris $\left(5 \times 10^{5}\right.$ cells/well/500 $\mu \mathrm{l}$ ) were incubated with HBMEC grown to monolayers in 24-well plates as previously described [9]. Plates were incubated at $37^{\circ} \mathrm{C}$ in $5 \% \mathrm{CO} 2$ incubator for $2 \mathrm{~h}$. HBMEC incubated alone in RPMI 1640 were used as negative controls. Each condition was performed in duplicate for each experiment. After this time the plates were removed and the wells gently mixed. Six $\mu 1$ was pipetted out from each well for a haemocytometer count. The counts were recorded. The numbers of $B$. mandrillaris recorded can be related to the numbers bound to the HBMEC since we know how many were inoculated into each well initially.

Adhesion assays in the presence of phospholipase inhibitors: To determine the involvement of phospholipases in B. mandrillaris binding to HBMEC, adhesion assays were performed in the presence of phospholipase inhibitors, i.e., cytidine 5'diphosphocholine, a $\mathrm{PLA}_{2}$ inhibitor; and compound $48 / 80$, a PLD inhibitor. These inhibitors were used at various concentrations. Briefly, various concentrations of inhibitors were incubated with B. mandrillaris for 30 min prior to adhesion assays. Adhesion assays were carried out as described above in the presence of inhibitors.

Cytotoxicity assays: To examine the pathogenic potential of each isolate used in this study, cytotoxicity assays were performed as previously described [10]. Briefly, B. mandrillaris isolates $\left(5 \times 3 \quad 10^{5}\right.$ parasites/well/500 $\mu$ l) were incubated with HBMEC monolayers in serum free media (RPMI 1640 containing $2 \mathrm{mM}$ glutamine, $1 \mathrm{mM}$ pyruvate and nonessential amino acids) at $37^{\circ} \mathrm{C}$ in $5 \% \mathrm{CO}_{2}$ incubator. HBMEC monolayers were observed periodically for cytopathic effects for up to $24 \mathrm{~h}$. At the end of this incubation period, cytopathic effects were assessed 
visually after hematoxylin staining. In addition, supernatants were collected and cytotoxicity was determined by measuring lactate dehydrogenase (LDH) activity release (Cytotoxicity detection kit; Roche Applied Science, Lewes, UK) as previously described [10]. This assay is based on the measurement of LDH activity released from damaged cells using the 96-well plates. Briefly, cell supernatant containing LDH catalyzes the conversion of lactate (solution from kit) to pyruvate, generating NADH and $\mathrm{H}^{+}$. In the second step, the catalyst (diaphorase, solution from kit) transfers $\mathrm{H}$ and $\mathrm{H}^{+}$from $\mathrm{NADH}$ and $\mathrm{H}^{+}$to the tetrazolium salt $p$ iodo-nitrotetrazolium (INT) yellow, which is reduced to formazan red, and absorbance is read at $492 \mathrm{~nm}$. Percentage LDH release was detected as follows: (sample value - control value / total LDH release control value $\mathrm{x} 100=\%$ cytotoxicity). Control values were obtained from HBMEC incubated alone. Total LDH release was determined from HBMEC $\begin{array}{llll}\text { treated with } \quad 1 \% & \text { Triton-X-100 (w/v). }\end{array}$

Cytotoxicity assays in the presence of phospholipase inhibitors: To determine the involvement of $\mathrm{PLA}_{2}$ and PLD in $B$. mandrillaris cytotoxicity to HBMEC, cytotoxicity assays were performed in the presence of phospholipase inhibitors. These inhibitors were used at various concentrations. Briefly, various concentrations of inhibitors were incubated with $B$. mandrillaris for over night prior to cytotoxicity assays. Cytotoxicity assays were carried out as described above in the presence of inhibitors

\section{RESULTS}

Balamuthia mandrillaris exhibit phospholipase $\mathbf{A}_{2}$ and phospholipase $\mathbf{D}$ activities: To determine whether B. mandrillaris exhibit phospholipase activities, assays were performed as described in materials and methods. Our results demonstrated that both $B$. mandrillaris isolates possess phospholipase $\mathrm{A}_{2}$ and phospholipase $\mathrm{D}$ activities. As observed in Fig. 1, $10^{6} \mathrm{~B}$. mandrillaris exhibited more than $0.1 \mathrm{U} / \mathrm{ml} \mathrm{PLA}_{2}$ activities, but showed up to $0.48 \mathrm{U} / \mathrm{ml}$ PLD activities. Interestingly, B. mandrillaris exhibited higher PLD than $\mathrm{PLA}_{2}$ activities.

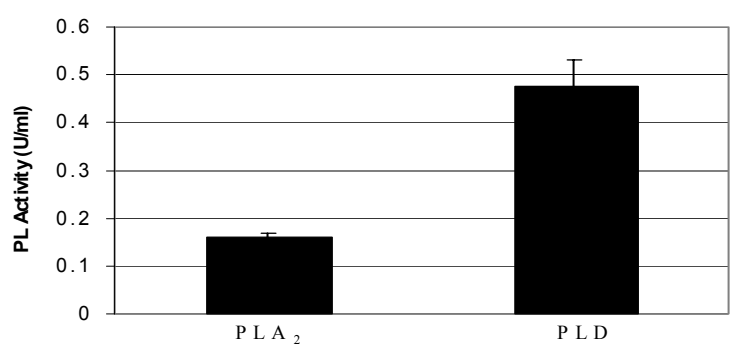

Fig. 1: Balamuthia mandrillaris exhibit phospholipase $\mathrm{A}_{2}$ and $\mathrm{D}$ activities.

Phospholipase $A_{2}$ and $D$ activities of $B$. mandrillaris are time-dependent: To determine the effects of time on phospholipase activities, assays were performed using various time intervals for up to $2 \mathrm{~h}$. As shown in Fig. 2, phospholipase activities are time-dependent. Maximal activities of $0.16 \mathrm{U} / \mathrm{ml}$ (for $\mathrm{PLA}_{2}$ ) and 0.48 $\mathrm{U} / \mathrm{ml}$ (for PLD) were observed after $2 \mathrm{~h}$. Again, higher PLD activities were observed as compared with PLA $_{2}$ activities.

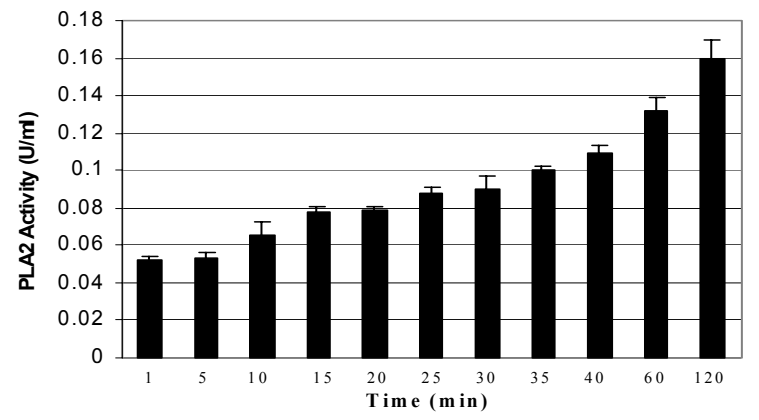

Fig.2:A). Phospholipase $\mathrm{A}_{2}$ activities of Balamuthia mandrillaris are time dependent.

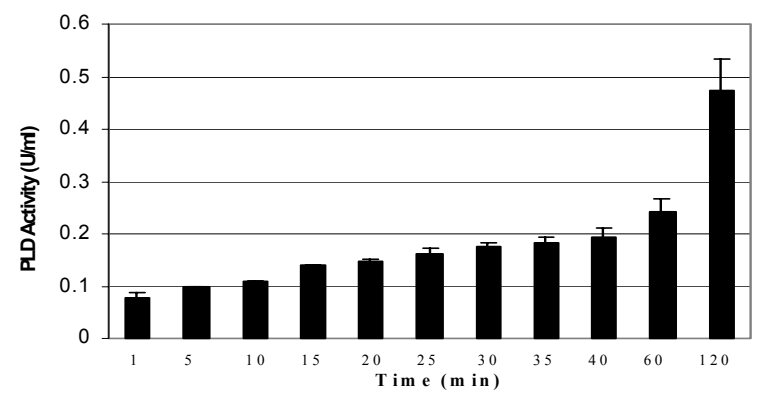

Fig.2:B). Phospholipase D activities of Balamuthia mandrillaris are time dependent. 
Maximal PLA $A_{2}$ and PLD activities were observed at $37^{\circ} \mathbf{C}$ : To determine the effects of temperature on phospholipase activities, various temperatures were tested. We observed optimal PLA 2 and PLD activities at $37{ }^{\circ} \mathrm{C}$, i.e., $0.144 \mathrm{U} / \mathrm{ml}$ and $0.255 \mathrm{U} / \mathrm{ml}$ respectively (Fig. 3). Interestingly, both $\mathrm{PLA}_{2}$ and PLD activities were inhibited at $60^{\circ} \mathrm{C}$. Overall, these findings suggest that B. mandrillaris exhibit optimal $\mathrm{PLA}_{2}$ and PLD activities at $37{ }^{\circ} \mathrm{C}$ indicating their physiological relevance.

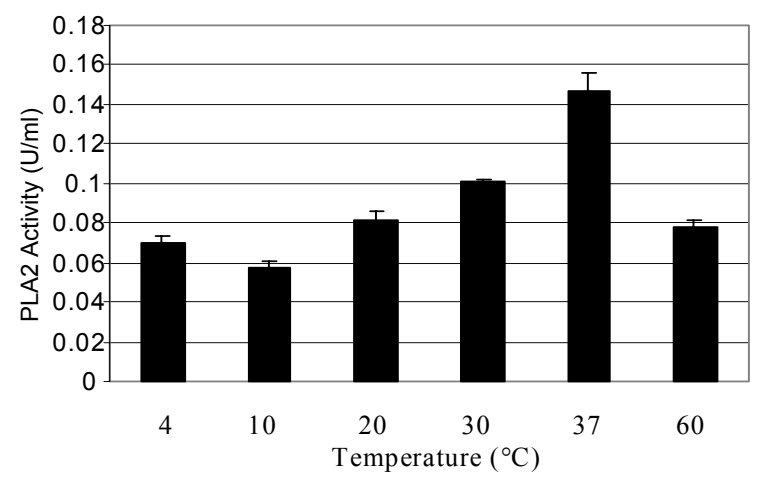

Fig.3: A). Maximal PLA 2 activities were observed at $37^{\circ} \mathrm{C}$.

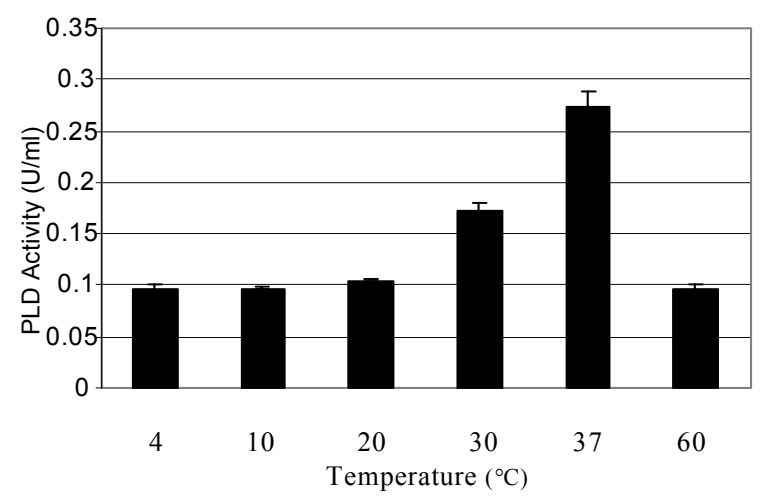

Fig.3: B). Maximal PLD activities were observed at $37^{\circ} \mathrm{C}$.

Maximal PLA $A_{2}$ and PLD activities were observed at pH 8: To determine the effects of $\mathrm{pH}$ on phospholipase activities, various pHs were tested. As shown in Fig. 4, that optimal PLA $\mathrm{P}_{2}$ and PLD activities were observed at pH 8 i.e., $0.178 \mathrm{U} / \mathrm{ml}$ and $0.53 \mathrm{U} / \mathrm{ml}$ respectively.

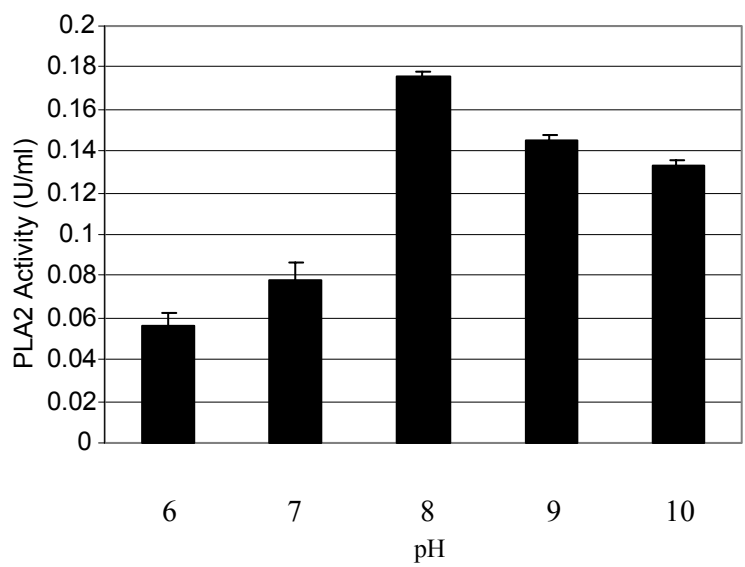

Fig.4:A). Maximal PLA $_{2}$ activities were observed at $\mathrm{pH} 8$

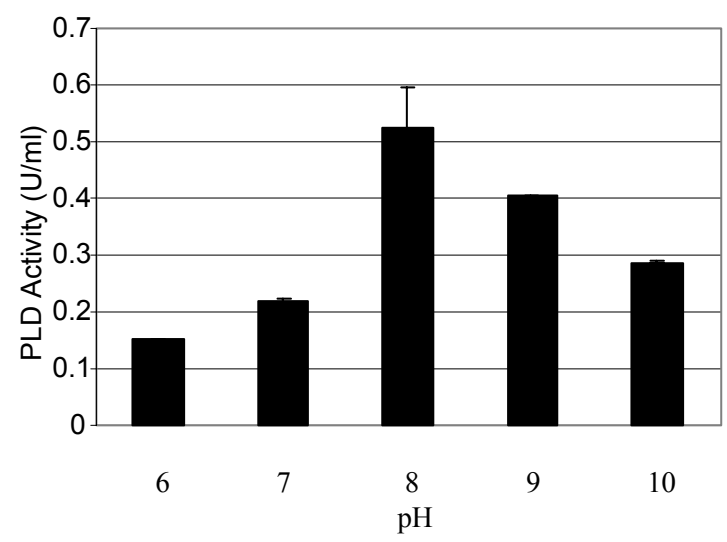

Fig. 4: B). Maximal PLD activities were observed at $\mathrm{pH} 8$

Balamuthia mandrillaris exhibited extracellular PLA $_{2}$ and PLD activities: To determine whether $B$. mandrillaris exhibit extracellular activities of $\mathrm{PLA}_{2}$ and PLD, assays were performed using $B$. mandrillaris conditioned medium. Conditioned medium were collected by incubating B. mandrillaris alone in RPMI and cell-free supernatants were collected by centrifugation and used in phospholipase assays as described in methods and materials. As observed in Fig. 5 , conditioned medium exhibited $\mathrm{PLA}_{2}$ and PLD activities, however their levels were significantly less than whole B. mandrillaris lysates. 


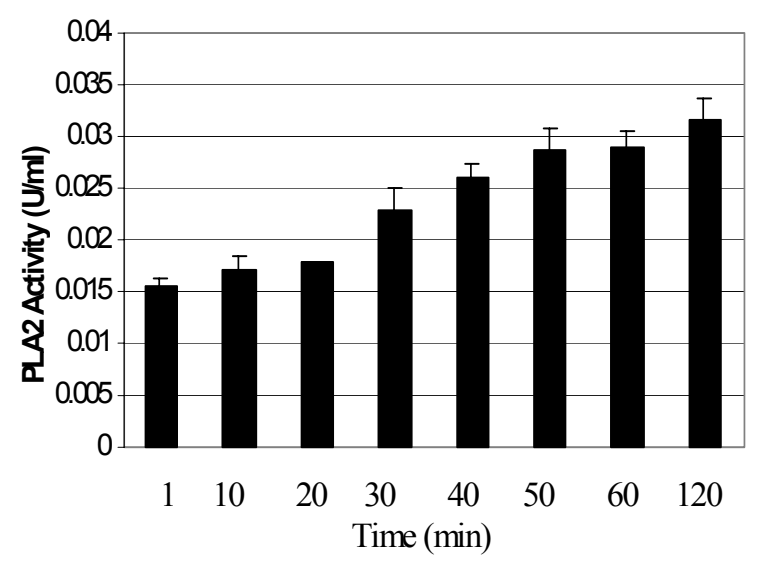

Fig.5:A). Balamuthia mandrillaris exhibited extracellular PLA 2 activities.

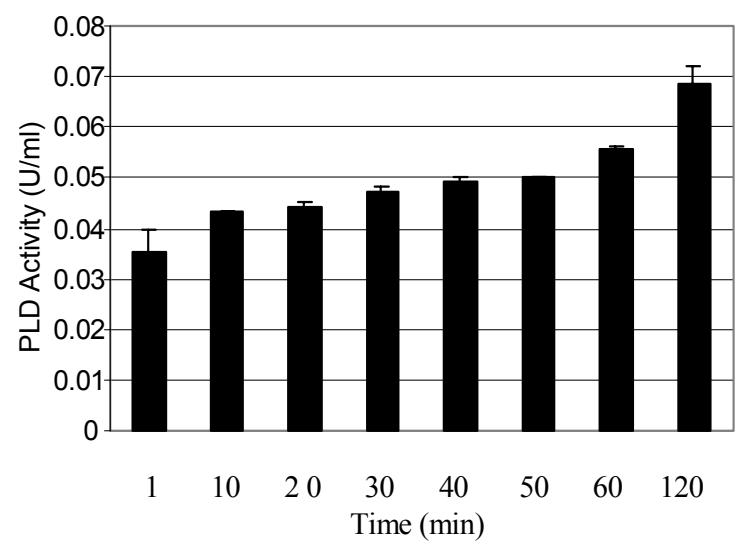

Fig.5B). Balamuthia mandrillaris exhibited extracellular PLD activities.

PLA $_{2}$ and PLD inhibitors partially inhibited $B$. mandrillaris binding to the host cells: In order to understand the $B$. mandrillaris adherence with the HBMEC, adhesion assays were performed in the presence and absence of phospholipase inhibitors. As shown in Fig. 6, these inhibitors play important roles to inhibit the binding of $B$. mandrillaris to HBMEC. It was observed that in the presence of cytidine $\left(\mathrm{PLA}_{2}\right.$ inhibitor) B. mandrillaris binding to HBMEC is $17 \%$ while in the presence of compound 48/80 (PLD inhibitor) this binding is more than $20 \%$.

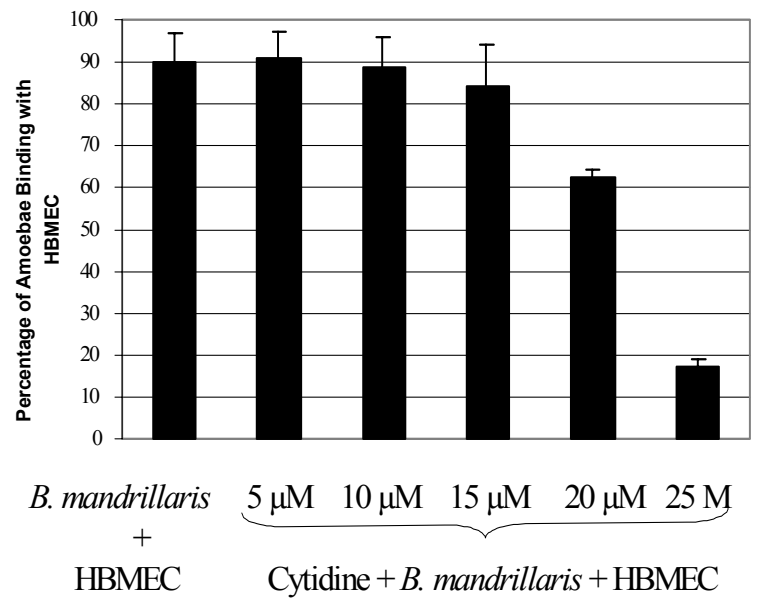

Fig.6:A). PLA 2 inhibitors partially inhibited Balamuthia mandrillaris binding to the host cells.

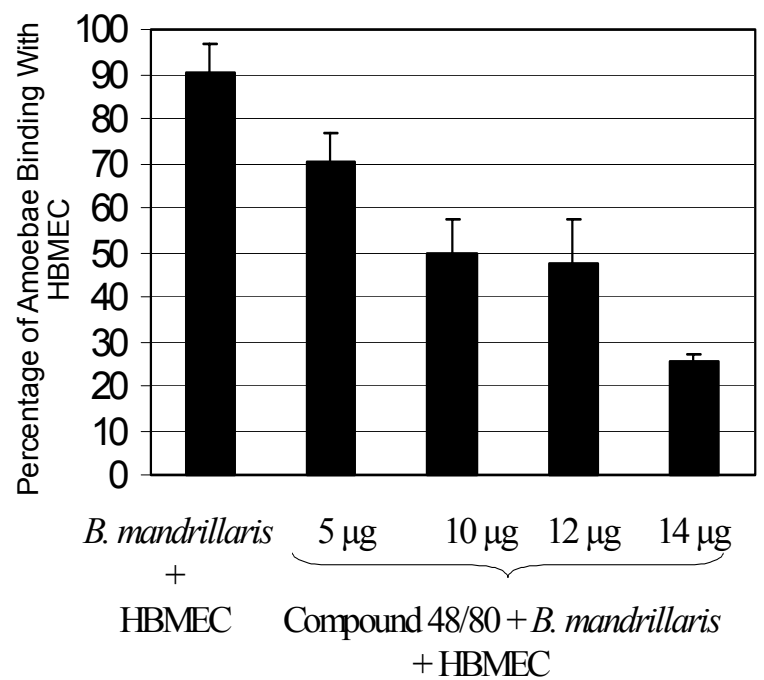

Fig. 6B). PLD inhibitors partially inhibited Balamuthia mandrillaris binding to the host cells.

PLA $_{2}$ and PLD inhibitors partially inhibited $B$. mandrillaris-mediated host cells cytotoxicity: The major tasks to perform these assays were to confirm $\mathrm{PLA}_{2}$ and PLD activities in $B$. mandrillaris, to understand $B$. mandrillaris roles in the blood brain barrier changes, to know how could we inhibit these activities and what is the effect of inhibitors on HBMEC. These assays were done by using cytidine ( $\mathrm{PLA}_{2}$ inhibitors) and compound 48/80 (PLD inhibitor). As shown in Fig. 7, these inhibitors inhibit $B$. mandrillaris-mediated host cell cytotoxicity. It was 
observed that B. mandrillaris in the presence of 25 $\mu \mathrm{M}$ cytidine and $15 \mu \mathrm{g}$ compound 48/80 showed decreased HBMEC cytotoxicity without showing significant cytotoxic effects on HBMEC.

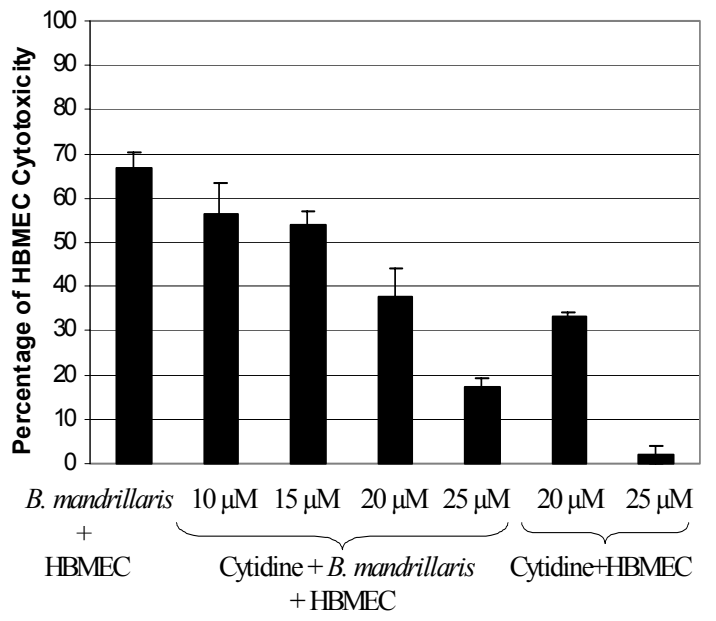

Fig.7A). PLA 2 inhibitors partially inhibited Balamuthia mandrillaris-mediated host cells cytotoxicity.

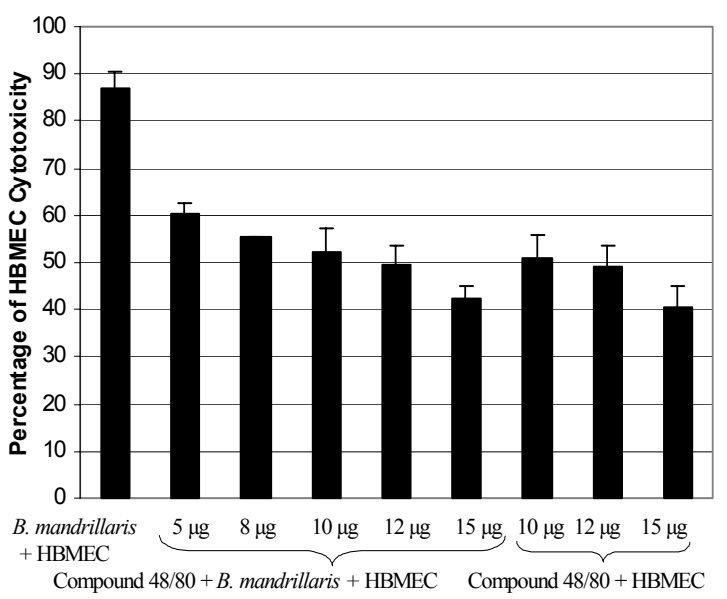

Fig.7B). PLD inhibitors partially inhibited Balamuthia mandrillaris-mediated host cells cytotoxicity.

\section{DISCUSSION}

Balamuthia mandrillaris is a causative agent of fatal granulomatous encephalitis in humans and other mammals. B. mandrillaris is believed to be widely distributed in the environment and dust through out the world. Human infection resulting from B. mandrillaris has increased significantly. There are more than 105 human cases of $B$. mandrillaris granulomatous encephalitis (BGE) reported through out the world. Previous reports show that B. mandrillaris can affect both healthy and immunocompromised patients but still there is no specific treatment for B.mandrillaris infections. Lack of effective treatment and delay in the diagnosis of most reported cases may have contributed to the high mortality rate. Earlier diagnosis and treatment with the known marginally effective agents may result in better clinical out comes. Several lines of evidence suggest that $B$. mandrillaris invasion of the central nervous system (CNS) is a result of haematogenous spread from the primary site of infection [11]. However, it is not clear how circulating amoebae cross the blood brain barrier. Thus understanding the molecular mechanism associated with B. mandrillaris-interactions with HBMEC and crossing the blood brain barrier may provide opportunities to develop novel strategies for treatment. Due to the ability of $B$. mandrillaris to penetrate host tissues, we hypothesize that this amoeba exhibits hydrolytic activities. In this study, for the first time we have shown the presence of phospholipase $\mathrm{A}_{2} \quad\left(\mathrm{PLA}_{2}\right)$ and phospholipase D (PLD) activities in $B$. mandrillaris. This is an important finding as both $\mathrm{PLA}_{2}$ and PLD have been shown to be important in the pathogenesis of other microbes including bacteria such as Vibrio parahaemolyticus [12] and Vibrio damsella [6]; fungal pathogens including Aspergillus fumigatus [13], and protozoans such as Acanthamoeba [14]. For example, Langton and Cesareo [15] have shown that $\mathrm{PLA}_{2}$ produced by Helicobacter pylori can degrade phosphatidylcholine-rich gut lining which can directly lead to gastric ulcer disease. Using $\mathrm{PLA}_{2}$-specific inhibitors, it was further shown that $H$. pylori were significantly less able to produce gastric ulcer in human [16] clearly indicating that $\mathrm{PLA}_{2}$ plays important roles in pathogenesis of disease. Similarly, Muckle and Gyles [17] have shown that PLD produced by Cornybacterium pseudotuberclosis causes increased vascular permeability and leads to the lymphadenitis or lymphangitis disease in ruminants or horses. This was 
further supported with the finding that PLD mutant of C. pseudotuberclosis might itself be used as a vaccine [18]. Similar roles may be attributed to B. mandrillaris phospholipases, however it remains to be determined. Among variable temperatures, the optimal $B$. mandrillaris phospholipase activities were observed at $37^{\circ} \mathrm{C}$. Similarly a range of $\mathrm{pH}$ was tested to determine the optimal activities and alkaline $\mathrm{pH}$ exhibited optimal activities indicating their physiological relevance.

Next we determined PLA P $_{2}$ and PLD activities in $B$. mandrillaris conditioned medium, which could suggest that both enzymes are extracellular. Our results showed that B. mandrillaris exhibit extracellular PLA $\mathrm{P}_{2}$ and PLD activities. These findings are novel as they suggest that $\mathrm{PLA}_{2}$ and PLD may be used as contactindependent virulence factors of $B$. mandrillaris. Next we tested the role of phospholipases on $B$. mandrillaris binding to the host cells as well as their cytotoxicity on the host cells. We made use of HBMEC as host cells and performed adhesion assays. Our findings revealed that in the presence of cytidine $\left(\mathrm{PLA}_{2}\right.$ inhibitors) $17 \%$ B. mandrillaris bind to the HBMEC and in the presence of compound 48/80 (PLD inhibitor) this binding increased up to $25 \%$. It is important to observe that in the absence of these inhibitors Balamuthia mandrillaris-mediated HBMEC binding increased up to $90 \%$ indicating that phospholipases of B. mandrillaris may play important roles in the HBMEC disruption. It is interesting to note that, of the two major phospholipases observed in this study, lectate dehydrogenase (LDH) assays in the presence of cytidine ( $\mathrm{PLA}_{2}$ inhibitor) showed only $17 \% \quad B$. mandrillaris-mediated HBMEC cytotoxicity while compound 48/80 (PLD inhibitor) showed only 42\% cytotoxicity which is an another evidence to prove that B. mandrillaris $\mathrm{PLA}_{2}$ and PLD are extracellular and play major roles in Balamuthia mandrillaris-mediated HBMEC cytotoxicity. These findings suggest that $B$. mandrillaris phospholipases play important roles in the blood brain-barrier changes. However, the precise targets and underlying mechanism of phospholipasesmediated HBMEC cytotoxicity remain unknown. It was also observed in adhesion and LDH assays that cytidine showed significant inhibition, which suggests that cytidine is a good inhibitor against $B$. mandrillaris $\mathrm{PLA}_{2}$. Moreover cytidine showed very less cytotoxic effects on HBMEC even at higher concentration which indicating that these inhibitors could be important for therapeutic interventions

\section{CONCLUSION}

In conclusion, we have shown for the first time that $B$. mandrillaris exhibit phospholipase activities i.e., phospholipase $\mathrm{A}_{2}$ and phospholipase $\mathrm{D}$ activities. Our results show that these phospholipases are involved in B. mandrillaris binding to HBMEC and play vital roles in $B$. mandrillaris-mediated HBMEC cytotoxicity, which may lead to amoebae traversal of the blood-brain barrier. Thus understanding the molecular mechanism associated with $B$. mandrillaris phospholipases may provide opportunities to develop novel strategies for treatment.

In this study we have shown the roles of phospholipases in B. mandrillaris virulence, the future work will be to use these enzymes in drug discovery efforts to identify and design inhibitors and/or their use as a vaccine. The utility of phospholipases as diagnostic markers of B. mandrillaris infections is yet another area of study that may prove to be fruitful.

\section{ACKNOWLEDMENTS}

This work was supported by a Grant of Habib Sons Bank Limited UK. This work was also supported by the special grant from Mr. S.N. Haider.

\section{REFERENCES}

1. Visvesvara, G. S., Martinez, A., Schuster, F. L., Leitch, G. J., Wallace, S. V., Sawyer, T. K. \& Anderson, M. 1990. Leptomyxid amoeba, a new agent of amoebic meningoencephalitis in humans and animals. J. Clin. Microbiol. 28, 2750-2756.

2. Anzil, A. P., Rao, C., Wrzolek, M. A., Visvesvara, G. S., Sher, J. H. \& Kozlowski, P. B. 1991. Amoebic meningoencephalitis in a patient with AIDS caused by a newly recognised opportunistic pathogen: Leptomyxid amoeba. Arch Pathol. Lab. Med. 115, 21-25.

3. Schuster, F. L., Glaser, C., Gilliam, S., \& Visvesvara, G. S. 2001. Survey of sera from encephalitis patients for Balamuthia mandrillaris antibody. J. Euk. Microbiol.

4. Schuster, F. L., Dunnebacke, T. H., Booton, G. C., Yagi, S., Kohlmeier, C. K., Glaser, C., Vugia, D., Bakardjiev, A., Azimi, P., Maddux-Gonzalez, M., Martinez, A. J. \& Visvesvara, G. S. 2003. Environmental isolation of Balamuthia mandrillaris associated with a case of amoebic encephalitis. J. Clin. Microbiol. 41, 3175-3180. 
5. Deetz T. R., Sawyer, M. H., Billman G., Schuster, F. L. \& Visvesvara, G. S. 2003. Successful treatment of Balamuthia amoebic encephalitis: presentation of 2 cases. Clin. Infect. Dis. 37, 13004-13012.

6. Kothary, M. H. \& Kreger, A. S. 1985. Purification and characterisation of an extracellular cytolysin produced by Vibrio damsella. Infect. Imuun.49,2531.

7. Alsam, S., Kim, K. S., Stins, M., Rivas, A. O., Sissons, J. \& Khan, N. A. 2003. Acanthamoeba interactions with human brain microvascular endothelial cells. Microb. Pathogen 35,35-241

8. Jayasekera, S., Sissons, J., Tucker, J., Rodges, C., Nolder, D., Walhurst, D., Alsam, S., Higgins, E. M., White, M. L. \& Khan, N. A. 2004. Postmortem culture of $B$. mandrillaris from the brain and cerebrospinal fluid of a case of granulomatous amoebic meningoencephalitis, using human brain microvascular endothelial cells. J. Med. Microbiol.53.1007-1012

9. Sissons, J., Alsam, S., Jayasekera, S., Kim, K. S., Stins, M., \& Khan, N. A. 2004. Acanthamoeba induces cell-cycle arrest in host cells. J. Med. Microbiol. 53, 711-717.

10. Sissons, J., Stins, M., Jayasekera, S., Alsam, S., \& Khan, N. A. 2005.Acanthamoeba induces celldeath via a phosphatidylinositol 3-kinase (P13K)dependent mechanism. Infect. Immun., 73, 27042708.

11. Visvesvara, G. S., Schuster, F. L. \& Martinez, A. J. 1993. Balamuthia mandrillaris, N.G., N. Sp., agent of amoebic meningoencephalitis in humans and other animals. J. Euk. Microbiol. 40, 504-514.
12. Shinoda, S., Matsuoaka, H., Tsuchie, T., Miyoshi, S.-I., Yamamoto, S., Tanniguchi, H. \& Miuguchi, Y. 1991. Purification and characterisation of a lecithin-dependent haemolysin from Escherichia coli transformed by a Vibrio parahaemolyticus gene. J.Gen. Microbiol. 137, 2705-11.

13. Birch, M., Robson, G. D., Law, L. \& Denning, D. W. 1996. Evidence of multiple extracellular phospholipase activities of Aspergillus fumigatus. Infect. Immun

14. Victoria, E. J. \& Korn, E. D. 1975. Enzymes of phospholipids metabolism in the plasma membrane f Acanthamoeba castellani. J. Lipid Res. 16 (1): 54-60.

15. Langton, S. R. \& Cesareo, S. D. 1992. Helicobacter pylori associated phospholipase $\mathrm{A}_{2}$ activity: a factor in peptic ulcer production. $J$. Clin. Pathol. 45, 221-4.

16. Ottlecz, A., Romero, J. J., Hazell, S. L., Graham, D. Y., \& Lichtenberger, L. M. 1993. Phospholipase activity of Helicobacter pylori and its inhibition by bismuth salts. Dig. Dis. Sci. 38, 2071-80

17. Muckle, C. A. \& Gyles, C. L. 1983. Relation of lipid content and exotoxin production to virulence of Cornybacterium pseudotuberclosis in mice. Curr. Microbiol. 13, 57-60.

18. Hodgson, A. L., Krywult, J., Corner, L. A., Rothel, J. S. \& Radford, A. J. 1992. Rational attenuation of Cornybacterium pseudotuberclosis: potential cheesy gland vaccines and live delivery vehicle. Infect. Immun. 60, 2900-5 